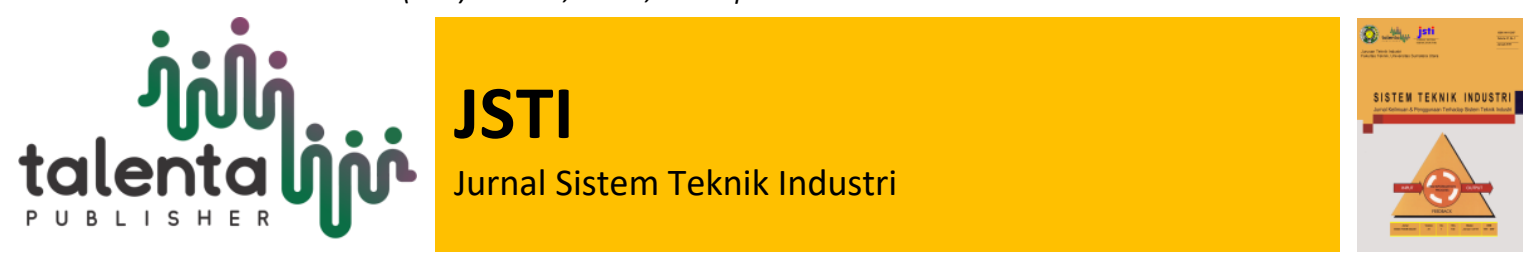

\title{
Analisa Performansi Pembangkit Listrik Siklus Rankine Organik Sederhana Dengan Sumber Panas Uap Geothermal Berkualitas Rendah
}

\author{
Andianto Pintoro ${ }^{1}$, Achmad Husein Siregar ${ }^{2}$ \\ ${ }^{1,2}$ Departemen Teknik Mesin, Fakultas Teknik, Universitas Sumatera Utara
}

\begin{abstract}
Abstrak. Pada tulisan ini dipaparkan tentang suatu kajian eksperimental yang telah dilakukan untuk menganalisa performansi dari sebuah unit pembangkit listrik sistim siklus Rankine organik (Organic Rankine Cycle) skala kecil yang memanfaatkan uap panas bumi berkualitas rendah sebagai sumber panas penggerak. Komponen-komponen utama dari unit pembangkit tersebut terdiri dari pompa tipe vane yang digunakan untuk menaikkan tekanan fluida kerja, evaporator dan kondensor sebagai alat penukar kalor serta turbin sebagai alat ekspansi, yang dibuat dari memodifikasi kompresor pendingin udara mobil jenis scroll. Sedangkan fluida kerja organik yang digunakan adalah R134a. Dari hasil pengujian ini didapat efisiensi termal sistim tertinggi sebesar 5,34\% dan daya keluaran bersih sebesar 1.523,42 watt. Hasil pengujian menunjukkan bahwa penggunakan uap panas bumi berkualitas rendah pada sebuah sistim pembangkit listrik ORC ini layak untuk digunakan dengan kinerja yang dapat diterima.
\end{abstract}

Kata Kunci: Uap panas bumi, Organic Rankine cycle, Energi baru terbarukan, Sistim pembangkit tenaga

\begin{abstract}
This paper describes an experimental study that has been carried out to analyze the performance of a small-scale Rankine Cycle (Organic Rankine Cycle) power generation unit that utilizes low-quality geothermal steam as a driving heat source. The main components of the generating unit consist of a vane type pump which is used to increase the working fluid pressure, evaporator and condenser as a heat exchanger and turbine as an expansion device, which is made from modifying the scroll air compressor type scroll. While the organic working fluid used is R134a. From the results of this test, the highest thermal efficiency of the system is 5.34\% and the net output power is 1,523.42 watts. The test results show that the use of low quality geothermal steam in an ORC power plant system is feasible to use with acceptable performance.
\end{abstract}

Keywords: Geothermal vapor, Organic Rankine cycle, Renewable new energy, Power generation system

Received 2 January 2019 | Revised 11 January 2019| Accepted 11 January 2019

*Corresponding author at: Jalan Raya Tlogomas 246 Malang

E-mail address: restuputri@umm.ac.id, dikawahyudin8@gmail.com 


\section{Pendahuluan}

Kebutuhan akan energi listrik sudah merupakan suatu kebutuhan mendasar pada kehidupan masyarakat di Indonesia. Ketersediaan energi listrik selalu berhubungan dengan ketersediaan sumber energi penggerak primernya, yang mana bahan bakar fosil masih memainkan peran yang dominan sebagai sumber energi primer untuk menghasilkan energi listrik tersebut. Dalam Indonesia Energy Outlook 2018 yang diterbitkan oleh Badan Pengkajian dan Penerapan Teknologi (BPPT) Indonesia, dituliskan bahwa 88\% dari total kebutuhan sumber energi untuk menghasilkan energi listrik di Indonesia berasal dari bahan bakar fosil (54\% dari batu bara dan $34 \%$ dari BBM dan gas). Ironisnya pada bagian lain disebutkan bahwa cadangan bahan bakar fosil di Indonesia terus mengalami pengurangan akibat dieksploitasi, sebagai contoh diperkirakan bahwa cadangan terbukti dari minyak bumi akan habis dalam kurun waktu 9 tahun. Hal ini seharusnya sudah menjadi pemikiran bagi kita untuk mulai mengurangi ketergantungan terhadap sumber energi fosil, selain penggunaan bahan bakar fosil akan menyebabkan banyak masalah lingkungan seperti pemanasan global dan polusi atmosfer. Sumber energi baru terbarukan dapat dijadikan sebagai sumber energi alternatif untuk mengurangi penggunaan sumber energi fosil, karena ketersediaannya cukup besar di Indonesia dan penggunaannya lebih bersahabat terhadap lingkungan.

Sebagaimana diketahui, Indonesia memiliki banyak sekali sumber-sumber energi alami yang potensial dan dapat dikembangkan untuk dikonversi menjadi energi listrik, seperti, energi angin, energi gelombang laut, energi matahari dan energi panas bumi. Di antara berbagai sumbersumber energi tersebut, sumber energi panas bumi merupakan sumber energi panas yang jumlahnya cukup besar di Indonesia yakni terdapat disebanyak 256 lokasi yang tersebar di Indonesia dan memiliki kapasitas sumber panas bumi potensial yang setara dengan 29,544 GW. Kapasitas ini merupakan $40 \%$ dari potensi geothermal dunia. Tetapi yang baru berhasil dimanfaatkan hanyalah sebesar 1,438 GW atau hanya sekitar 4,87\% saja, Indonesia Energy Outlook 2018, BPPT. Salah satu hal yang harus diatasi dalam memanfaatkan uap panas bumi tersebut adalah kualitas uap panas bumi yang ada tersebut banyak yang berkualitas rendah ( $\mathrm{P}<$ 3 bar dan $\mathrm{T}<200 \mathrm{oC}$ ), yang mana uap dalam kondisi seperti ini tidak dapat digunakan untuk menggerakkan turbin seperti pada sistim pembangkit tenaga yang biasa digunakan di Indonesia, yakni sistim pembangkit tenaga yang menggunakan siklus Rankine konvensional. Sumber panas berkualitas rendah seperti ini sebenarnya masih dapat dimanfaatkan untuk membangkitkan energi listrik, tetapi siklus pada sistim pembangkit yang digunakan harus dimodifikasi sedikit agar dapat digunakan. Siklus Rankine organik (Organic Rankine Cycle, $O R C$ ) adalah suatu siklus yang sudah terbukti pemakaiannya dalam mengkonversikan sumber panas bersuhu rendah menjadi energi listrik, siklus ini merupakan mofifikasi dari siklus Rankine konvensional dengan merubah fluida kerjanya menjadi fluida organik (contoh : refrigerant $R 245 f a, R 123)$ menggantikan air.

Sistim pembangkit listrik ORC ini mempunyai kelebihan dapat memanfaatkan sumber panas bersuhu rendah karena sifat alami dari fluida organik yang digunakan yaitu mempunyai titik didih cukup rendah ( $\mathrm{R} 245 \mathrm{fa}$ mempunyai titik didih pada $\mathrm{T}=15^{\circ} \mathrm{C}$ dan $\mathrm{P}=1,01$ bar). Sedangkan 
kelemahannya adalah nilai efisiensi termal sistim yang rendah berkisar dalam rentang $4 \%$ hingga $8 \%$.

Telah banyak dilakukan kajian- kajian tentang sistim pembangkit tenaga yang menggunakan ORC sebagai siklus penggerak, diantaranya adalah Yamamoto T. et al. secara eksperimental telah menunjukkan bahwa penggunaan fluida kerja yang memiliki titik didih rendah pada sistem ORC, seperti R-123, dapat menghasilkan kinerja siklus yang lebih baik daripada menggunakan air untuk suhu saluran masuk turbin di bawah 120oC. Sedangkan A.A. Lakew and O. Bolland menganalisa kemampuan produksi daya dan persyaratan ukuran peralatan untuk beberapa fluida organik seperti R123, R227ea, R245fa, R290 dan n-pentane. Mereka menggunakan siklus Rankine organik pada keadaan subkritis tanpa pemanasan lanjut dan menggunakan suhu sumber panas dalam kisaran suhu dari $80 \mathrm{oC}$ hingga $200 \mathrm{oC}$ serta menggunakan tekanan evaporator sebagai parameter independen. Hasil studi mereka menunjukkan bahwa pemilihan fluida kerja tergantung pada jenis sumber panas, tingkat suhu dan tujuan desain. Qiu et al. memberi gambaran tentang perangkat ekspansi/turbin untuk sistem ORC mikro- CHP dan menyimpulkan bahwa kompresor jenis scrool dan vane yang dimodifikasi baik digunakan sebagai turbin pada sistim pembangkit ORC dengan kisaran daya keluaran antara 1-10 kW.

Kajian penelitian ini bertujuan untuk menganalisa performansi/kinerja dari sistim pembangkit tenaga listrik yang dirancang, dengan menggunakan sistem Organic Rankine Cycle (ORC) dan memanfaatkan sumber panas dari uap panas bumi berkualitas rendah sebagai sumber energi penggerak. Metode yang digunakan adalah pendekatan analisa kualitatif dengan studi eksperimental.

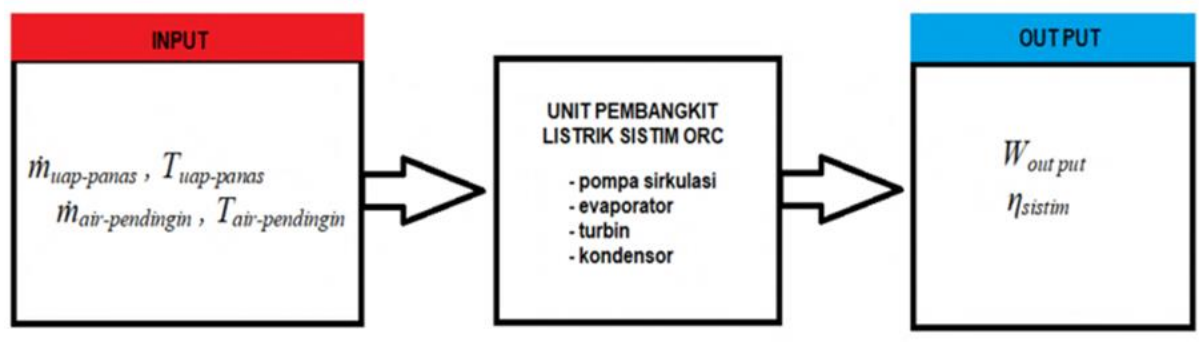

Figure 1 Blok Diagram Analisa Performansi Sistem ORC

\section{Landasan Teori}

Sistem Organic Rankine Cycle (ORC) adalah suatu siklus Rankine konvensional yang dimodifikasi dengan menggunkan fluida kerja dari jenis fluida organik menggantikan air yang digunakan pada siklus Rankine konvensional. Fluida organik ini mempunyai sifat fisik yang menguap pada suhu yang cukup rendah sehingga tidak memerlukan sumber panas yang tinggi untuk merubah fasenya menjadi uap panas lanjut (superheated). Sedangkan komponen utama yang digunakan adalah sama dengan siklus Rankine konvensional, seperti pompa, evaporator, turbin dan kondensor. Dapat dilihat pada Gambar1 skema diagram dari sistim ORC, fluida kerja dalam keadaan cair jenuh, titik (1), dinaikkan tekanannya oleh pompa sirkulasi fluida kerja, titik (2), dan masuk ke evaporator untuk dipanaskan oleh sumber panas bersuhu rendah, akibat 
pemanasan pada tekanan tetap di evaporator, fluida kerja berubah fase menjadi uap jenuh, titik (3), kemudian fluida kerja yang telah dalam fase uap jenuh dan bertekanan ini diekspansikan hingga ke tekanan kondensasi titik (4), yang mana proses ekspansi ini menghasilkan kerja pada poros turbin/ekspander yang disambung langsung dengan generator listrik sehingga putaran poros generator tersebut akan menghasilan listrik, di kondensor panas yang dikandung fluida kerja dibuang kelingkungan hingga fluida kerja berubah fase kembali menjadi cair jenuh, titik (1).

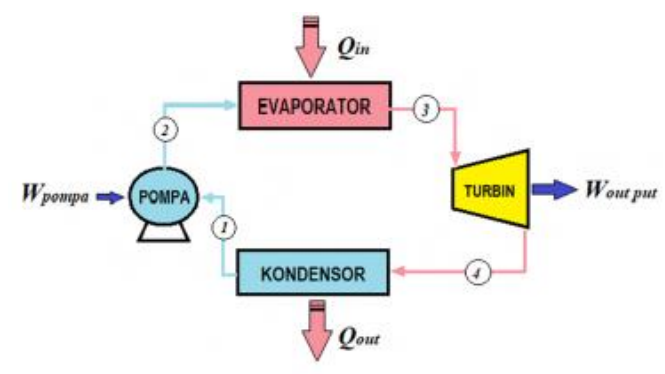

Figure 2 Skema Sistem ORC

\section{Metode Penelitian}

Penelitian ini dilakukan di Laboraturium Power Plant Departemen Teknik Mesin, Fakultas Teknik Universitas Sumatera Utara mulai dari bulan Maret 2018 hingga bulan Oktober 2018. Metode yang digunakan adalah eksperimental kualitatif dimana peralatan uji dirancang, dibangun dan diuji untuk dapat melakukan analisa performansinya. Suhu uap sumber panas (uap panas bumi) dijadian variabel bebas yang dibuat berubah-ubah dalam rentang suhu antara $80 \mathrm{oC}$ hingga $100 \mathrm{oC}$, sedangkan tekanan dan suhu fluida masuk turbin dijadikan sebagai variabel terikat. Untuk laju aliran massa fluida kerja, uap pemanas, media pendingin dan tekanan kondensor ditentukan berdasarkan kondisi maksimum yang dapat dicapai.

\subsection{Analisa Termodinamik dari Sistem ORC}

Gambar 3 menggambarkan proses termodinamika untuk sistim ORC, merupakan tahapantahapan proses pada siklus Rankine teoritis yang terdiri dari proses-proses sebagai berikut: 1 -> 2: Proses menaikkan tekanan fluida kerja pada pompa sirkulasi; 2 -> 3: Proses pemanasan fluida kerja pada tekanan tetap di evaporator; 3 -> 4: Proses ekspansi fluida kerja pada turbin; 4 -> 1 : Proses pembuangan panas dari fluida kerja di kondensor.

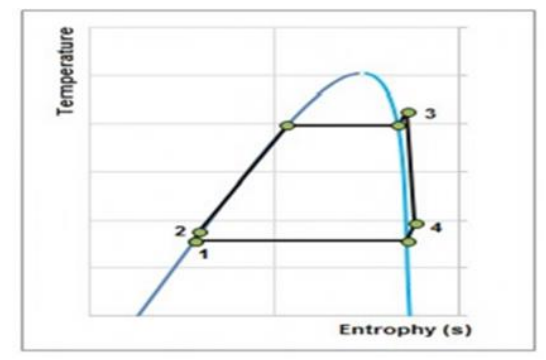

Figure 3 T-S Diagram untuk Sistem ORC 
Analisa siklus terdiri dari penerapan keseimbangan massa dan energi untuk setiap proses yang disebutkan di atas. Proses $1 \rightarrow 2$ adalah pekerjaan yang dilakukan oleh pompa sirkulasi fluida kerja dimana besarnya kerja yang dilakukan pompa sirkulasi aadalah sebesar:

$W_{\text {pompa }}=\left(h_{2}-h_{1}\right) / \eta_{p}$

Proses $2 \rightarrow 3$ adalah proses pemanasan fluida kerja oleh sumber panas di evaporator, dimana besarnya panas yang ditransfer adalah sebesar:

$Q_{\text {evap. }}=\left(h_{3}-h_{2}\right)$

Prooses $3 \rightarrow 4$ adalah besar kerja/ekspansi aktual dari fluida kerja di turbin, yakni sebesar:

$W_{\text {turbin }}=\left(h_{3}-h_{4}\right) \cdot \eta_{m} \cdot \eta_{s}$

Proses $4 \rightarrow 1$ adalah proses kondensasi atau pelepasan panas yang dikandung fluida kerja hingga menjadi fase cair jenuh di kondensor dengan menggunakan media pendingin, dan besarnya panas yang dilepas adalah sebesar:

$Q_{\text {kond. }}=\left(h_{4}-h_{1}\right)$

Besarnya keluaran daya listrik yang dibangkitkan pada sistim ORC ini adalah sebesar:

$W_{\text {siklus }}=W_{\text {turbin }}-W_{\text {pompa } 1}-W_{p_{\text {ompa }}}(c w)$

Sedangkan besarnya effisiensi termal dari sistim ORC adalah :

$\eta_{\text {siklus }}=W_{\text {siklus }} / Q_{\text {evap }}$

\subsection{Experimental Set-Up dan Sistem Pengukuran}

Berdasarkan dari disain sistim pembangkit yang direncanakan, prototipe pembangkit listrik sistim ORC skala kecil dirancang, dibangun, dan diuji. Gambar 3 adalah diagram skematik dari experimental Set-Up. Prototipe alat uji eksperimental terdiri dari evaporator, steam generator, turbin (ekspander) yang dibuat dari sebuah kompresor AC mobil jenis scroll yang telah dimodifikasi, kondensor, pompa umpan, menara pendingin (cooling tower) dan pompa air pendingin. Fluida kerja organik yang digunakan dalam penelitian ini adalah R134a.

Sistim pengukuran dan akuisisi data yang digunakan dalam penelitian ini adalah menggunakan thermocoupel untuk mengukur suhu, pressure transducer untuk penukuran tekanan, digital turbine flowmeter untuk pengukuran laju aliran massa fluida yang diletakkan pada tempattempat yang ditentukan seperti pada Gambar 2. Kesemuaan alat ukur tersebut terhubung dengan data logger merek Cole Palmer tipe 18200-20 yang terhubung dengan sebuah PC untuk merekam data hasil pengukuran. 


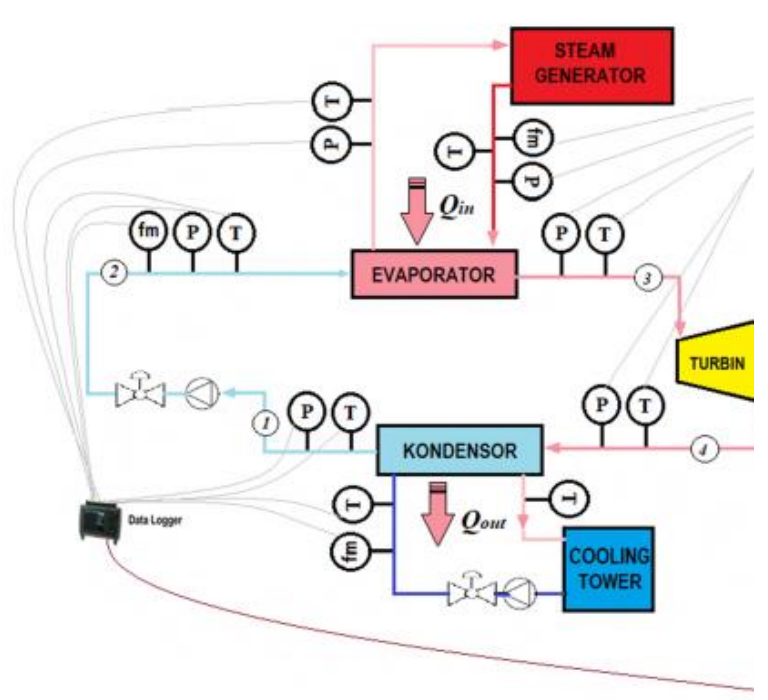

Figure 4 Diagram Experimental Set-Up

Gambar 3 menggambarkan proses termodinamika untuk sistim ORC, merupakan tahapantahapan proses pada siklus Rankine teoritis yang terdiri dari proses-proses sebagai berikut: 1 -> 2: Proses menaikkan tekanan fluida kerja pada pompa sirkulasi; 2 -> 3: Proses pemanasan fluida kerja pada tekanan tetap di evaporator; 3 -> 4: Proses ekspansi fluida kerja pada turbin; 4 -> 1: Proses pembuangan panas dari fluida kerja di kondensor.

Komitmen diperlukan pada suatu proses perbaikan kualitas agar perbaikan yang melibatkan secara seimbang antara sisi manusia dan sisi teknologi. Kaizen adalah istilah dari bahasa Jepang pada konsep Continous Incremental Improvement. Kai yang memiliki arti perubahan dan Zen memiliki arti baik. Kaizen yaitu penyempurnaan dan berkesinambungan yang mana melibatkan semua orang. Kaizen merupakan suatu kesatuan pandangan yang yang komprehensif dan terintegrasi yang bertujuan untuk melaksanakan perbaikan secara terus-menerus. Pengertian falsafah 5S yaitu (Gaspersz \& Fontana, 2007) :

a. Seiri adalah dengan menyisihkan barang yang dianggap tidak diperlukan dan barang yang dianggap tidak diperlukan di tempat kerja dibuang. Merupakan langkah awal dalam menjalankan budaya 5S, yaitu membuang/menyortir/ menyingkirkan barang-barang, file-file yang tidak digunakan lagi ke tempat pembuangan. Semua barang yang ada di lokasi kerja, hanyalah barang yang benar-benar dibutuhkan untuk aktivitas kerja. Tindakan dilakukan agar tempat penyimpanan menjadi lebih efisien, karena dipergunakan untuk menyimpan barang atau file yang memang penting dan dibutuhkan, serta bertujuan juga agar tempat kerja terlihat lebih rapi dan tidak berantakan. Keuntungan yang akan didapat dalam menerapkan Seiri (Ringkas-Sisih- Keteraturan-Pemilahan-Sort):

1. Kuantitatif:

a. Penghematan pemakaian ruangan.

b. Persediaan dan produk barang yang bermutu. 
c. Kecepatan waktu pencarian barang/dokumen yang dibutuhkan.

2. Kualitatif:

a. Tempat kerja lebih aman.

b. Suasana kerja lebih nyaman.

c. Mencegah tempat/alat/bahan menjadi rusak lebih awal.

b. Seiton (susun) adalah dengan menata peralatan kerja yang digunakan dengan rapi dan menghilangkan kegiatan mencari agar alat-alat tersebut bisa dengan mudah ditemukan secara cepat. Setelah menyortir semua barang atau file yang tidak dipergunakan lagi, pastikan segala sesuatu harus diletakkan sesuai posisi yang ditetapkan, sehingga selalu siap digunakan pada saat diperlukan. Pastikan bahwa:

1. Setiap barang punya tempat.

2. Setiap tempat punya nama untuk barang tertentu.

3. Buat menjadi terorganisir dan sistematis.

4. Beri nama pada setiap tempat penyimpanan yang mudah diingat, dapat

5. menggunakan kode pada tempat penyimpan:

a. Bila berbentuk barang, berikan label dengan nama atau visual sebagai ciri khas.

b. Bila berbentuk file atau softcopy data, atur semua folder di komputer.

c. Pastikan agar mudah mengidentifikasi, saat file, barang ataupunbenda tersebut dibutuhkan, sehingga tidak perlu membuang banyak waktu untuk mencarinya.

c. Seiso adalah dengan memelihara kebersihan pada tempat kerja. Setelah menjadi rapi, langkah berikutnya adalah membersihkan tempat kerja, ruangan kerja, peralatan dan lingkungan kerja. Tumbuhkan pemikiran bahwa kebersihan merupakan hal yang fital dalam kehidupan, jika kita tidak menjaga kebersihan, lingkungan akan menjadi kotor dan menjadi faktor utama terjangkitnya penyakit tidak nyaman. Menyebabkan berkurangnya produktivitas dan berakibat banyak kerugian. Lakukanlah pembersihan harian, pemeriksaan kebersihan dan pemeliharaan kebersihan.

Seiketsu adalah dengan mempertahankan seiri, seiton, dan seiso agar proses tersebut bisa berlangsung secara terus-menerus. Tahap ini adalah tahap yang sukar. Untuk menjaga ketiga tahap yang sudah dijalankan sebelumnya secara rutin. Tahap ini dapat juga disebut tahap perawatan, merupakan standarisasi dan konsistensi dari masing-masing individu untuk melakukan tahapan-tahapan sebelumnya. Membuat standarisasi dan semua individu harus patuh pada standar yang telah ditentukan. Dapat dimotivasi dengan memberikan hadiah atau hukuman.

d. Setsuke adalah suatu bentuk kedisiplinan yang mana hal tersebut menjadi kebiasaan, sehingga para pekerja menjadi biasa mematuhi peraturan dan dilaksanakan penyuluhan kepada para pekerja agar dapat bekerja dengan profesional. Pemeliharaan kedisiplinan pribadi meliputi suatu kebiasaan dan pemeliharaan program $5 \mathrm{~S}$ yang sudah berjalan. Bila berada pada posisi sebagai atasan, buatlah standarisasi $5 \mathrm{~S}$ serta berikan pelatihan $5 \mathrm{~S}$, agar 
seluruh karyawan perusahaan dapat mengerti akan kegunaan dari 5S sebagai dasar kemajuan perusahaan, karena dengan menerapkan $5 \mathrm{~S}$ yang praktis dan ringkas bertujuan pada efisiensi, pelayanan yang baik, keamanan bekerja serta peningkatan produktivitas dan profit.

Manfaat dari penerapan budaya 5R (5S) di tempat kerja yaitu :

a. Produktivitas menjadi lebih meningkat disebabkan pengaturan di tempat kerja yang lebih efisien.

b. Kenyamanan menjadi lebih meningkat disebabkan pada tempat kerja menjadi selalu bersih serta lebih luas dan lapang.

c. Bahaya yang ada di tempat kerja menjadi lebih berkurang hal ini disebabkan kualitas pada tempat kerja menjadi lebih baik.

d. Penghematan bertambah hal ini dikarenakan dapat pemborosan di berbagai tempat kerja dapat dikurangi.

Konsep 5R / 5S yaitu merupakan proses perubahan sikap dengan cara menerapkan aspek penataan, kebersihan dan kedisiplinan di tempat kerja. Dengan menerapkan prinsip "A place for everything and every thing in its place" maka setiap anggota organisasi dibiasakan bekerja dalam lingkungan kerja dengan standar tempat yang jelas (Hirano, 1996).

Pada konsep 5R / 5S juga bagian dari konsep kaizen yang memiliki arti penyempurnaan secara berkesinambungan pada kehidupan pribadi, kehidupan di keluarga, lingkungan sosial ataupun juga tempat kerja (Imai, 1986). Konsep 5R/5S juga mengenai budaya bagaimana pekerja dapat memperlakukan tempat kerja dengan benar. Jika pada tempat kerja dapat tersusun dengan rapi, bersih, tertib sehingga kemudahan bekerja perorangan bisa diciptakan. Hal ini berarti pada kemudahan bekerja dapat dicapai empat bidang sasaran pokok industri yang meliputi :

- $\quad$ Efisisensi Kerja

- Produktifitas dalam bekerja

- Kualitas dalam bekerja

- Keselamatan dalam bekerja yang bisa lebih mudah dipenuhi.

Pemenuhan dalam saran pokok ini adalah syarat pada industri dalam bertumbuh kembang sehingga manfaatnya dapat dinikmati bukan bagi perusahaan saja, tetapi juga bagi pekerja. Untuk kegiatan 5S sebelum dimulai, ada hal yang harus dilakukan pertama kali yaitu dengan mengambil foto di tempat kerja. Hal ini akan memiliki manfaat sebagai perbandingan dengan keadaan sebelumnya jika konsep 5R/5S dapat dikerjakan sepenuhnya (Hirano, 1996).

\section{Hasil dan Pembahasan}

Pada percobaan ini, untuk pengambilan data performansi sistim, dilakukan dalam waktu 10 menit dengan keadaan sistim berada dalam keadaan steady-state. Setiap kondisi operasi seperti perbedaan tekanan, putaran turbin serta keadaan fluida kerja pada saluran masuk turbin dalam 
keadaan uap panas lanjut (superheated) dilakukan dengan mengontrol temperatur sumber panas, laju aliran massa sistim dan beban generator. Pada Gambar 5 dapat dilihat variasi efisiensi sistim dan net power output akibat pengaruh dari perubahan suhu sumber panas, semakin bertambahnya suhu sumber panas maka nilai effisiensi sistim dan net power output semakin naik, yang mana dalam rentang suhu uap sumber panas yang diujikan effisiensi sistim terbaik didapat pada suhu sumber panas sebessar $100^{\circ} \mathrm{C}$ yakni sebesar $5,34 \%$ dan besarnya daya output bersih $1.523,42$ watt.

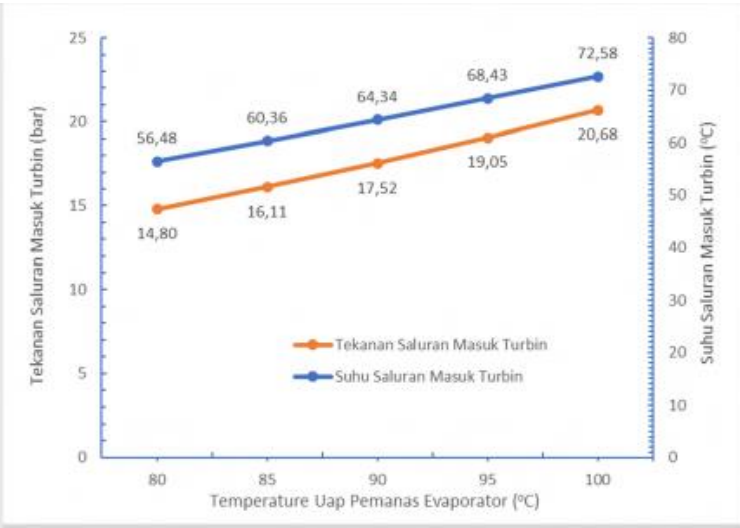

Figure 5 Pengaruh Perubahan Suhu Uap Pemanas Terhadap Net Power Output Dan Effisiensi Sistim

Sedangkan pada Gambar 6 dapat kita lihat bahwa semakin naik suhu uap pemanas di evaporator maka akan semakin tinggi suhu dan tekanan fluida kerja masuk ke turbin/ekspander sehingga menyebabkan naiknya net output power sistim. Naiknya suhu dan tekanan fluida kerja ini berarti nilai entropy fluida kerja juga bertambah besar sedangkan tekanan kondensasi dibuat konstan pada 4 bar.

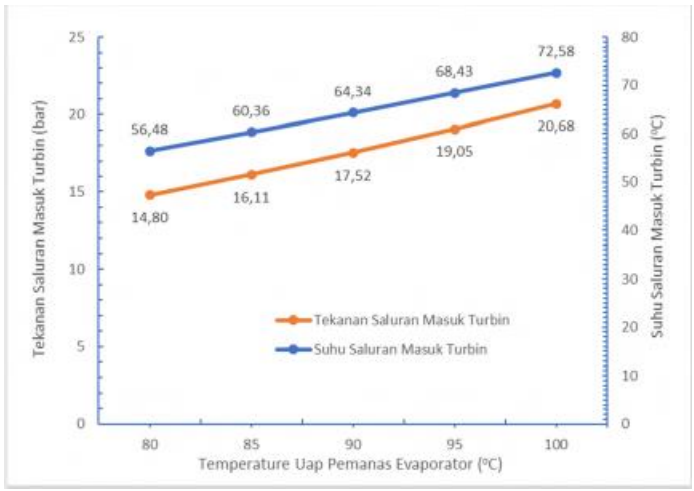

Figure 6 Pengaruh Perubahan Suhu Uap Pemanas Terhadap Suhu Dan Tekanan Pada Saluran Masuk Turbin

Pada Gambar 7 kita lihat pengaruh dari kenaikan suhu uap pemanas terhadap kerja pompa sirkulasi, dimana daya dikonsumsi pompa sirkulasi fluida kerja semakin besar seiring dengan kenaikan suhu uap pemanas evaporator, hal ini menunjukkan semakin besar kerja pompa sirkulasi untuk menaikkan tekanan pada evaporator dan juga berarti bertambahnya laju aliran massa fluida kerja untuk setiap perubahan suhu uap pemanas. 


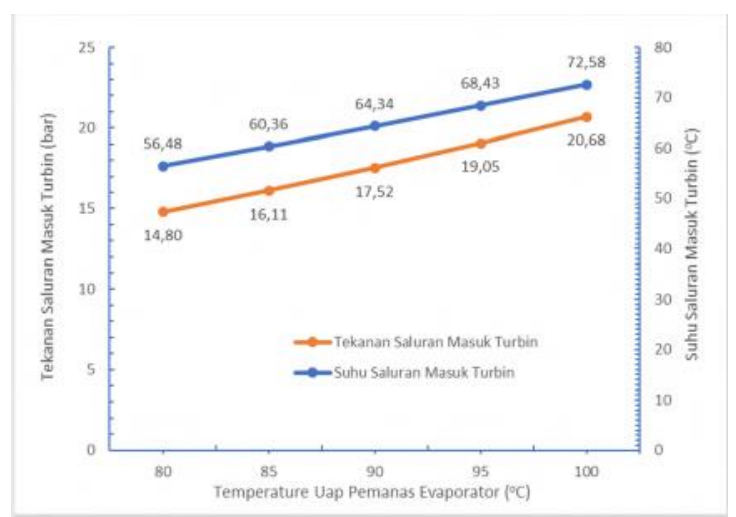

Figure 7 Pengaruh Dari Kenaikan Suhu Uap Pemanas Terhadap Kerja Pompa Sirkulasi Dan Net Power Output

\section{Kesimpulan}

Studi eksperimental yang bertujuan untuk menganalisa performansi atau unjuk kerja dari sistim pembangkit listrik yang menggunakan siklus Rankine organik dan memanfaatkan uap panas bumi berkualitas rendah sebagai sumber panas/penggerak telah dilakukan. Sistim ini memanfaatkan kompresor AC mobil jenis scrool yang telah dimodifikasi sebagai turbin/ekspander. Sedangkan fluida kerja organik yang dipakai adalah dari jenis refrigeran R134a dan disirkulasikan oleh sebuah pompa sirkulasi jenis pompa vane. Untuk sumber panas, digunakan pembangkit uap (steam generator) mini sebagai tiruan dari sumber uap panas geothermal. Adapun hasil analisa performansi dari sistim pembangkit ini diperoleh sebagai berikut.

a. Siklus dioperasikan dalam keadaan panas lanjut (superheated).

b. Efisiensi siklus meningkat dengan meningkatnya suhu pemanasan.

c. Efisiensi siklus maksimum yang daya keluaran bersih (Net Power Output) adalah sebesar 1.523,42 watt dengan kecepatan rotasi 1535 lebih kurang 40 RPM dan tekanan kondensasi dibuat konstan sebesar 4 bar.

d. Laju aliran massa fluida kerja, laju aliran massa uap pemanas dan laju aliran massa air pendingin dikondisikan pada keadaan maksimum.

\section{REFERENSI}

[1] BPPT, Indonesia Energy Outlook 2018, Center for Assessment of Process and Energy Industries, 2018

[2] Yamamoto T, Furuhata T, Arai N, Mori K. Design and testing of the Organic Rankine Cycle, Energy 2001; 26:239-251.

[3] A A Lakew A A, Bolland O. Working fluids for low-temperature heat source, Applied Thermal Engineering 2010; 30:1262-1268

[4] Qiu G, Liu H, Riffat S. Expanders for micro-CHP systems with organic Rankine cycle, Applied Thermal Engineering 2011; 31:3301-3307

[5] Lemort V, Declaye S, Quoilin S, Experimental characterization of a hermetic scroll expander for use in a micro-scale Rankine cycle. Proc. IMechE Part A: Journal of Power and Energy 2011; 226: 126-136

[6] Moran M J, Shapiro H N, Fundamentals of Engineering Thermodynamics, Second Edition, SI Version, John Wiley \& Sons. Inc.New York 1993 
[7] Chang J C, Hung T C, He Y L, Zhang W. Experimental study on low-temperature organic Rankine cycle utilizing scroll type expander.Applied Energy 2015; 155:150159

[8] Badr O, O'Callaghan PW, Hussein M, Probert S D. Multi-vane expanders as prime movers for low- grade organic Rankine cycle engines. Applied Energy 1984; 16:129146

[9] Madhawa H D, Golubovic M, Worek W M, Ikegami Y. Optimum Design Criteria for an ORC using Low-Temperature Geothermal Heat Sources. Energy 2007; 23:16981706

[10] Quoilin S, Lemort V, Lebrun J, Experimental study and modeling of an Organic Rankine Cycle using scroll expander, Applied Energy 2010; 87:1260-1268

[11] Wang J, Yan Z, Wang M, Ma S, Dai Y, Thermodynamic analysis and optimization of an (organic Rankine cycle) ORC using low grade heat source, Energy 2013; 49:356365 